REPERTÓRIO

LIVRE

\title{
EM DEFESA DE UMA MÁQUINA DE GUERRA CULTURAL
}

\author{
DEFENDING A MACHINERY \\ OF CULTURAL WAR \\ EN DEFENSA DE UNA MÁQUINA \\ DE GUERRA CULTURAL
}

SIDMAR GOMES

PRISCILLA CARBONE 


\section{RESUMO}

A presente reflexão, ao tomar como pano de fundo embates contemporâneos acerca de duas matrizes de teatro, uma de inspiração conservadora e outra progressista, intenta lançar luz sobre o tema das alianças entre estratégias políticas de governo e práticas teatrais, friccionando acontecimentos históricos brasileiros a comentários publicados em redes sociais por representantes da classe teatral. Segundo investe esta reflexão, ao eleger como inspiração o trato arquivístico e crítico legado do pensador francês Michel Foucault, tal discursividade daí advinda incitaria a operacionalização de uma maquinaria de governo da população via as práticas teatrais, aqui entendidas não apenas como práticas atinentes aos processos criativos, mas também como os discursos e a racionalidade a eles inerentes.

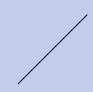

\begin{abstract}
The current thinking has as a backdrop contemporary clashes concerning two theatre sources, one has a conservative inspiration and the other a progressive one. The aim is to bring light over the alliance theme between government policy strategies and theatrical practices, colliding Brazilian historic events with comments published in social media by representatives of the Brazilian theatre class. According to this analysis, the moment that is chosen as an inspiration is the archival arrangement and critical legacy of French thinker Michel Foucault and such discursive position would urge to the operationalization of a governmental machinery to its society through theatrical practices, here understood not only as practices pertaining to creative processes, but also as the discourses and rationality inherent in them.
\end{abstract}

\section{RESUMEN}

La reflexión actual, que toma como telón de fondo los enfrentamientos contemporáneos sobre dos matrices teatrales, una de inspiración conservadora y la otra progresiva, pretende arrojar luz sobre el tema de las alianzas entre las estrategias del gobierno político y las prácticas teatrales, relacionando los acontecimientos históricos brasileños con los comentarios publicados en las redes sociales por representantes de la clase de teatro. De acuerdo con esta reflexión, al elegir como inspiración el legado de archivo y crítico del pensador francés Michel Foucault, dicho discurso resultante de esto incitaría a la operacionalización de una maquinaria de gobierno de la población a través de prácticas teatrales, entendidas aquí no solo como prácticas relacionadas con procesos creativos, pero también como los discursos y la racionalidad inherentes a ellos.

\section{Palavras-chave:} história do teatro; governamento; pedagogia do teatro; práticas teatrais; cultura.

\section{KEYWORDS:}

theatre history; governance; theater pedagogy; theatrical practices; culture.

\section{Palabras clave:} historia del teatro; gobernancia; pedagogía teatral; prácticas teatrales; cultura. 


\section{APRESENTAÇÃO}

No DIA 18 DE JUNHo DE 2019 teve início uma ampla polêmica teatral travada na esfera virtual, via rede social Facebook. O reconhecido dramaturgo e diretor Roberto Alvim, fundador do coletivo Club Noir, publicou em seu perfil pessoal o seguinte:

Caros, peço a todos os atores, diretores de teatro, dramaturgos, professores de artes cênicas, cenógrafos, figurinistas, iluminadores e sonoplastas, que se alinham aos valores conservadores no campo da arte do TEATRO, que enviem mensagens para o email teatrobrasileirodearte@outlook.com com seus currículos. Estamos montando um grande banco de dados de artistas de teatro conservadores. E peço também que todos compartilhem essa mensagem (postem no Twitter tbm, por favor) para que chegue ao máximo de pessoas por todo o Brasil. Vamos criar uma máquina de guerra cultural! MUITO OBRIGADO e que Deus Ihes abençoe! (ALVIM, 2019)

Na ocasião, Alvim havia sido convidado pelo presidente em exercício Jair Bolsonaro para ocupar o cargo de diretor do Centro de Artes Cênicas da Fundação Nacional das Artes (Funarte)), órgão sob a batuta da Secretaria Especial da Cultura do 
Ministério da Cidadania. Sete horas depois de sua primeira publicação, o dramaturgo e diretor fez uma nova postagem esclarecendo o objetivo de sua proposta:

\author{
[...] o que propus foi a criação de um BANCO DE DADOS de artistas \\ que amam a História e as realizações perpetradas por homens e \\ mulheres que, desde a Grécia Antiga, vêm dedicando suas vidas \\ à dignificação de nossa humanidade e ao desvelamento da com- \\ plexidade da condição humana. (ALVIM, 2019)
}

Alvim afirmou querer edificar um “teatro de arte" com pessoas que tivessem o mesmo desejo que ele, por isso a necessidade de criação do tal banco de dados. Segundo declara, “alinhar-se a valores conservadores em arte” não significa necessariamente "apoiar o atual governo":

JAMAIS disse que, para fazer parte desse banco de dados, seria necessário apoiar o atual governo. Mas não posso me furtar à minha convicção de que, sem o conhecimento e o amor aos clássicos, a criação de obras de arte se torna impossível hoje. Está claro? O que estou formando é um banco de pessoas interessadas em TEATRO DE ARTE em nosso país. (ALVIM, 2019)

O que seria, portanto, para Alvim (2019) um teatro de arte? Aproximadamente uma hora depois, ele esclareceu:

\begin{abstract}
O que estou propondo é um RENASCIMENTO da arte e da cultura nacionais a partir da redescoberta dos CLÁSSICOS. Fazer do palco palanque ideológico éjustamente o AVESSO desta proposta. Busco criar uma rede de artistas que amem profundamente a História de nosso Teatro, a ponto de ambicionarem a construção de grandeza equivalente HOJE. ISSO É CONSERVADORISMO, PORRA!
\end{abstract}

A repercussão do anúncio, somada à série de postagens posteriores, logo incitou algumas centenas de comentários divididos entre aqueles que apoiavam e rechaçavam a iniciativa. O termo "máquina de guerra cultural” se tornou o título recorrente das manchetes da imprensa que veicularam o acontecimento cibernético. 
O que estaria em disputa ao se evocar tal conceito? O próprio Alvim (2019) esclareceu o termo: “[...] quanto à ideia de 'máquina de guerra cultural’ - o conceito se refere ao combate entre erigir OBRAS DE ARTE contra DESTRUIR o conceito de obra de arte. Estou do lado de quem deseja ERIGÍ-LAS, é claro".

Podem achar que estou sonhando alto demais, mas o termo guerra cultural, ou máquina de cultura, significa fomentar o resgate dos clássicos, dos melhores autores e talentos em suas mais diversas searas estéticas, do passado e do presente, trazendo para as novas gerações o contato com o universal, com o atemporal, sem fronteiras ou categorias. Por que devemos reduzir a categorias ideológicas a arte, que é expressão humana universal? (ALVIM, 2019)

Alvim estaria interessado em reviver os clássicos circunscrevendo textos da Grécia Antiga, como os de autoria da tríade Sófocles, Ésquilo e Eurípedes, da Inglaterra Elisabetana, por exemplo, os textos escritos pela pena de William Shakespeare, além de textos clássicos nacionais, mais especificamente do teatro moderno brasileiro, tais quais as dramaturgias de Nelson Rodrigues. Valorizaria, portanto, escritores que foram de alguma forma consagrados por uma historiografia do teatro a qual atribuiu a determinados autores valores simbólicos que serviriam de referência para a construção da identidade epistemológica do que se denominou como “teatro". O que o diretor propõe não se interessaria por resgatar qualquer texto teatral escrito em algum momento da humanidade por qualquer pessoa, mas sim aquelas dramaturgias criadas por um grupo seleto de escritores, os quais, legitimados, comporiam as estruturas de uma história naturalizada e recorrente tanto do teatro brasileiro quanto do teatro ocidental. Sendo assim, Alvim oporia um teatro de arte, interessado em reapresentar os tais clássicos consagrados, a um suposto teatro de não arte, obras que, em sua visão, não possuiriam qualidade estética, mas por outro, esbanjariam dirigismos ideológicos.

Aproximadamente 24 horas após as primeiras publicações de Alvim em seu perfil do Facebook, Kil Abreu, diretor e curador do Núcleo de Artes Cênicas do Centro Cultural São Paulo, instituição pública administrada pela municipalidade da cidade 


\section{de São Paulo, optou por engrossar as discussões em curso proferindo o seu ponto de vista, também via as redes sociais:}

Que falta de consideração com o artista! Depois de ganhar calos na língua de tanto lamber as botas do führer, o diretor Roberto Alvim levou só o troféu abacaxi. Um carguinho no segundo escalão de uma fundação cultural falida. Se a Funarte já era aquela dificuldade toda nos governos petistas e sob a liderança de pessoas seríssimas, imaginem agora no meio dessa patacoada. E começa no pior estilo ‘volta surreal ao passado'. Ao invés de propor uma política pública para o teatro, o governo vai criar, se é que isso vai acontecer, uma Companhia Nacional. Imaginário totalmente Séc. XIX. A proposta é aberração de cabo a rabo. Além do gosto retrô e do atraso em termos de política pública, não seria a Companhia de teatro do Brasil, seria a companhia de teatro DO GOVERNO! Para quem subiu esse degrau e meio de poder gritando contra o que chamava de ‘aparelhamento da cultura’ pela esquerda, parece piada pronta. Mas não é só. Se quiser entrar nesse trem fantasma o artista camarada ainda tem que cantar a senha e se declarar 'de direita', segundo o critério definido pelo grande irmão. Pergunte o porquê e vem a resposta: 'para evitar a ideologia'!!! Hahaha. Mas o escandaloso aqui é justamente o viés 100\% ideológico do chamado! E o show não acaba: no decreto baixado ontem pelo diretor ele declara que sua missão na terra - para a honra de Deus e de Bolsonaro - é esta e que tem que ser assim porque ‘o teatro de direita é mais poético que o de esquerda'. Ui. Independente do que isso signifique (quem sabe?), coitadxs dxs artistas que não estão interessadxs nestes enquadramentos. De qualquer maneira a fórmula ‘filosófica' da empreitada é a seguinte (segura!): uma mistura de positivismo no nível básico 1 + o sequestro de uma (veja, só uma) frase de Deleuze - Guattari (mas eles não têm culpa alguma por isso), sob a luz de Olavo de Carvalho. E uma boa forçada de barra, óbvio, pra que tudo faça algum sentido. Ou seja, loucura, loucura. É uma chacina: a filosofia, a política, a linguagem - sintaxe e semântica - castigadas até a morte no 
pau-de-arara do pensamento confuso. De todo modo a proposta

já conta com o apoio indispensável de Regina Duarte e de Carlos Vereza. Agora vai. (ABREU, 2019, grifo do autor)

Como nota-se, Abreu vê como anacrônica a iniciativa de Alvim de querer fundar uma companhia nacional de teatro administrada pelo aparato estatal e uma escola de teatro destinada à formação de atores. Alvim declarou que ambicionava formar uma "Companhia de Teatro Brasileiro para percorrer o País encenando peças clássicas e uma grande escola de teatro" no mesmo dia em que publicou seu anúncio para o recrutamento de artistas conservadores. Kil Abreu, prontamente se opôs à ideia, dizendo que essa não seria uma "política pública para o teatro", e que a companhia, se montada, não estaria a favor do interesse da nação, mas sim do "Governo". Abreu ainda compararia a iniciativa proposta por Alvim com a atitude de artistas que se filiaram ao governo Nazista alemão cujas obras produzidas serviram de publicidade ao programa de governo higienista de Adolf Hitler. O próprio Alvim legitimaria a tese de Abreu. Alçado, em outubro de 2019, ao cargo de Secretário Especial de Cultura, meses depois Alvim seria exonerado por ter divulgado um vídeo institucional no qual parafraseava Joseph Goebbels, Ministro da Propaganda na Alemanha Nazista, fato que gerou repúdio por parte de diversas organizações.

No âmbito da polêmica deflagrada, a presente reflexão, portanto, intenta lançar luz sobre o tema das alianças entre estratégias políticas de governo e práticas teatrais, assunto incontestadamente inerente ao acontecimento acima descrito. Não se pretende equacionar a questão e tampouco aludir a um desfecho, mas sim friccionar alguns eventos históricos brasileiros a comentários publicados no calor da atualidade, os quais, segundo investe esta reflexão, incitariam a operacionalização de uma maquinaria de governo da população via as práticas teatrais. Nesta perspectiva, entende-se governo não apenas como instância governamental, administrativa, central, relacionada às ações do Estado, mas sim como ponto de intersecção "entre as tecnologias de dominação sobre os outros e as tecnologias de si". (FOUCAULT, 2004, p. 324)

Para tanto, elege-se como inspiração metodológica o legado crítico de Michel Foucault no que se refere ao seu trabalho sobre o arquivo, já que o presente 
interesse é pautado pelo questionamento de como algo, neste caso as práticas teatrais, teriam sido pensadas em uma dada época e pelo cruzamento destas com práticas sociais, éticas, políticas, artísticas etc. Tal pensador francês ressalva que não tinha por objetivo empreender um trabalho de historiador. O que o animava era tentar descobrir por que e como se estabeleceriam relações entre os acontecimentos discursivos, já que seríamos inextricavelmente ligados a eles: “em um certo sentido, não somos nada além do que aquilo que foi dito, há séculos, meses, semanas...". (FOUCAULT, 2006, p. 258)

Dessa forma, objetivando desnaturalizar práticas, e tomando o presente pela perspectiva crítica da inquietude que resulta de uma mirada que relativiza o passado reavivando um legado que parecia adormecido, será feita uma remissão ao século XIX, a partir da rememoração de dois significativos conflitos bélicos nacionais.

\section{UMA GUERRA E UMA COMPANHIA NACIONAL DE TEATRO}

A primeira guerra que o Brasil participou após a independência foi a Campanha da Cisplatina (1825-1828). O insucesso das tropas brasileiras nesse conflito explicitou alguns entraves que demandavam urgentes soluções: o baixo contingente de pessoal, as deserções dos soldados no meio da batalha e, por fim, a falta de motivação e de preparo técnico dos combatentes nacionais.

Na fase inicial do exército brasileiro, o recrutamento se dava de duas maneiras. Os cadetes, que eram geralmente filhos de oficiais da Guarda Nacional, ou membros de famílias comprovadamente aristocráticas, gozavam de privilégios e tinham vantagens financeiras. Já os praças eram recrutados à força e não gozavam de nenhuma regalia, pelo contrário, ganhavam pouco e ainda podiam ser açoitados: “proceder-se-á ao recrutamento forçado e o recrutado servirá por seis anos, receberá somente soldo simples, será conduzido preso ao quartel e nele conservado 
em segurança até que a disciplina o constitua em estado de se lhe facultar maior liberdade". (HOLANDA; PINHEIRO; FAUSTO, 2006, p. 189)

O recrutamento à força consistia em uma verdadeira caçada humana, em que policiais locais, tropas militares e até mesmo senhores de terra e outras autoridades, tais como juízes de órfãos, capturavam os indivíduos considerados desocupados ou desordeiros. Diferente dos cadetes, tais recrutas eram membros da marginalidade: criminosos que cumpriam suas penas e pobres que não conseguiam comprovar o exercício de atividades regulares. (GUIMARÃES, 2014) Nesse caso, o recrutamento fazia as vezes de regulador da ordem social, espécie de medida correcional, servindo de "castigo" aos indivíduos menos quistos pela sociedade. (JUNQUEIRA, 2005)

Por outro lado, o recrutamento também não era bem visto pelos habitantes, uma vez que qualquer cidadão poderia ser capturado de modo arbitrário, a menos que o capturado tivesse recursos para custear a sua soltura, o que não era o caso da maioria da população.

Põe-se em movimento no recrutamento forçado um jogo de gato-e-rato: os recrutadores usam de todos os expedientes e ardis para completar suas cotas, e os recrutáveis potenciais, de sua parte, realizam esforços desesperados de evasão ou adequação às circunstâncias de isenção. (MENDES, 1999 apud SOUZA 2013, p. 4)

Ademais, acabava-se arrebanhando os trabalhadores agrícolas: quando os recrutadores chegavam as lavouras eram abandonadas, os homens simplesmente fugiam das mãos dos aliciantes e os que não tinham tal sorte eram levados pela tropa. Assim, o recrutamento também era visto como um entrave ao desenvolvimento econômico, pois impedia que a mão de obra se fixasse ao longo do território nacional. (SOUZA, 2013)

No início do século XIX, o recrutamento era hostilizado e a reputação do exército não era a das melhores, o desempenho dos recrutados deixava a desejar e muitos conseguiam escapar. Tornava-se necessário, primeiramente, formar um 
exército estável que garantisse a permanência dos soldados. Era preciso, também, capacitar os soldados a manusear as novas armas que chegavam da Europa, a artilharia exigia um outro tipo de distribuição dos soldados no espaço e outra expertise física dos combatentes. Por fim, era importante começar a desenvolver um pensamento estratégico e tático de guerra. Tornava-se necessário incutir um sentimento de confiança em relação ao recrutamento e à tropa nacional. Até o fim desse conflito, os habitantes se identificavam mais com o local que moravam do que com uma certa ideia de país, e/ou nação. Foi preciso, portanto, primeiro fomentar a criação de símbolos que unissem as pessoas em torno de um mesmo ideal. A ideia de nação e a edificação de seus símbolos, fomentada pela guerra, muito corroborou para unir simbolicamente os habitantes dispersos pelo território brasileiro.

A história sabida do teatro brasileiro reza haver um artista originário do século XIX e considerado o precursor da modernização do teatro nacional: João Caetano dos Santos. Nascido no Rio de Janeiro no ano de 1808, João Caetano estreou nos palcos aos 23 anos de idade, desempenhando papeis de coadjuvante em companhias portuguesas. A figuração ou o anonimato não pareceu ser o destino desse artista. Em 1833, almejando maior protagonismo em cena, Caetano fundou sua própria Cia., a Companhia Nacional João Caetano, a qual passou a ocupar o recém-aberto Teatro São Pedro de Alcântara, na cidade do Rio de Janeiro.

Para os historiadores que coadunam com essa história sabida, João Caetano é considerado o primeiro ator nacional de destaque por criar uma companhia que falava português brasileiro, que montava, além dos textos clássicos, textos de autores nacionais, por reconhecer um valor dito elevado da arte teatral e por exigir dos atores considerável comprometimento no que tange ao fazer teatral. Como aponta o crítico Sábato Magaldi:

O grande intérprete João Caetano dos Santos havia formado [...] uma companhia brasileira, a fim de ‘acabar assim com a dependência de atores estrangeiros para o nosso teatro'. Recebendo, ao que parece, papéis menores em conjuntos portugueses, por causa do ciúmes artístico, João Caetano sentiu necessidade de organizar companhia própria, no mesmo espírito de 
Como ressalta a historiadora Rosyane Trotta (FARIA; GUINSBURG, 2013) João Caetano dos Santos teria sido o primeiro artista a receber financiamento do Estado para a manutenção de sua companhia teatral, bem como também foi o primeiro artista a solicitar a abertura de uma escola de formação de atores igualmente financiada pela esfera pública.

Em 1956, foi publicado em forma de livro uma coletânea dos escritos de João Caetano dos Santos sob o nome de Lições Dramáticas. Originalmente, os textos foram publicados no periódico Jornal do Comércio, em 1861. Justifica que a iniciativa teria se dado pelo desejo de prestar um bom serviço à arte teatral, a qual possuiria uma missão de bastante relevância na formação dos bons hábitos dos cidadãos: "A idéia de ser útil à cena do meu país animou-me a escrever êste trabalho [...]. O teatro, bem organizado e bem dirigido, deve ser um verdadeiro modêlo de educação, capaz de inspirar na mocidade o patriotismo, a moralidade e os bons costumes". (SANTOS, 1956, p. 7)

A partir deste ponto a história recorrente do teatro brasileiro escreveria o nome de João Caetano como um dos primeiros a reconhecer a importância superior das práticas teatrais como plataforma para o alcance de valores nacionalistas e moralizantes. $\mathrm{O}$ teatro como modelo de educação, capaz de incitar nas jovens gerações o patriotismo, a moralidade e os bons costumes, funcionaria, então, como um dispositivo para a construção de determinados valores que começariam a ser caros a um país em que a formação da ideia de nação se tornava condição fundamental para a administração de suas fronteiras e de sua população.

Neste ponto, cabe apontar-se que João Caetano dos Santos foi cadete do exército brasileiro, servindo na Campanha da Cisplatina. $\mathrm{O}$ ator chegou a receber elogio do general Duque de Caxias, menos por sua atuação nos palcos, e mais por sua atuação como cadete na batalha em questão, tal como afirma seu primeiro biógrafo, Moraes Filho (1903, p. 4): “mereceu elle, ao que sabemos, pela galhardia nos combates, animações e elogios do general, mais tarde Duque de Caxias". Assim, "o moço batalhador" que "trocou a farda do soldado pela vestidura e cothurno da 
tragedia grega”. (MORAES FILHO, 1903, p. 7) diz ter sido “a idéia de ser útil à cena” de seu país (SANTOS, 1956, p. 7) o que o animou a escrever as referidas Lições Dramáticas, contando que “o Augusto Nome de Vossa Majestade Imperial fôsse a égide que o defendesse e amparasse". (SANTOS, 1956, p. 5)

Portanto, tendo tal experiência como berço de sua formação moral e cívica, investe a presente reflexão no exercício de aproximação entre a experiência deste ator no interior de um exército nacional e, posteriormente, a proposição de suas práticas teatrais. Como se verá, essa aproximação se dá não somente pelo crivo das perspectivas ideológicas e táticas de uma milícia de Estado, mas sobretudo, pela forma de organização e justificativa das ações e pretensões artísticas de João Caetano.

A solicitação de abertura do que seria o primeiro Conservatório Nacional de Teatro foi enviada por João Caetano ao Marquês de Olinda. Porém, a iniciativa sequer logrou resposta. Por esforços próprios, o ator, então, empreendeu uma pequena escola no Teatro São Pedro, a fim de formar atores e criar um júri dramático incumbido de premiar textos nacionais. Porém, ao que parece, a iniciativa não vingou:

\begin{abstract}
Mais de um ano decorreu desde êstes trabalhos primitivos da escola dramática até a sua criação, delonga devida a não se haverem efetuado matrículas de alunos, circunstância que ainda hoje se dá, e que fará morrer a instituição; os poucos que se apresentaram na abertura do júri vão pouco a pouco abandonando as preleções, se bem que, à exceção de três ou quatro do sexo masculino, todos os mais são sem vantagens físicas, nem dotes intelectuais. (SANTOS, 1956, p. 82)
\end{abstract}

O motivo de tão baixo quórum é justificado pelo "fato de ser a escola um estabelecimento particular, sem oferecer garantias nem futuro aquêles que a frenquentarem". (SANTOS, 1956, p. 82) A solução seria, portanto, dar "a êste ramo tão útil um caráter oficial". (SANTOS, 1956, p. 83)

Quais seriam os procedimentos sugeridos para a oficialização e manutenção da escola? 
O primeiro, de acordo com indicação de João Caetano, seria a isenção dos alunos de prestarem o serviço da guarda nacional e da tropa de linha. Dada a experiência já sabida de João Caetano, vale ressaltar-se dois de seus valores: a latente preocupação em defender e proteger a pátria, somada ao grande empenho de fazer do teatro um meio útil à sociedade. Como aliar ambos os interesses? A dispensa do serviço militar configura-se, portanto, como uma espécie de atrativo ao investimento do cidadão em sua formação teatral. Assim como a milícia de Estado ocuparia o cidadão salvaguardando-o da vagabundagem e garantindo-Ihe formação civilizatória, uma pretensa formação teatral também o tornaria, além de livre da vadiagem, empenhado na empreitada de um teatro dedicado à defesa eà disseminação do patriotismo, da moralidade e dos bons costumes, fundamentais, também, à proteção nacional.

Complementar ao primeiro pedido, Caetano acrescentaria a importância de os candidatos ao Teatro Nacional serem gratificados com alguma quantia financeira ao longo da formação. Assim como eram gratificados os cadetes da escola militar, era necessário oferecer aos futuros atores a garantia de um trabalho regular no Teatro Nacional, sob as expensas do governo.

Como dito, tal sonho de uma escola de teatro edificante e necessária proposto por Caetano não se realizou efetivamente. Incumbir as práticas teatrais da capacidade de promover sentimentos de patriotismo e bons costumes, evidenciaria o quanto, naquele momento, tais valores eram prezados. A construção de símbolos que unificassem um grupo de pessoas em torno de algo chamado “nação”, foi um dos objetivos dessa guerra fracassada, a qual necessitava de voluntários patriotas e confiantes não só na força do exército, mas unidos em prol da construção de uma identidade coletiva, assim como a empreitada posterior de um Teatro Nacional.

Após 37 anos da Campanha da Cisplatina, o Brasil se envolveria em outro conflito, a Guerra do Paraguai (1865-1870). Dessa experiência se efetivariam as mudanças inauguradas no conflito anterior. João Caetano dos Santos faleceu dois anos antes do início da Guerra do Paraguai, portanto, não pôde presenciar as transformações que se sucederiam a partir desse ponto no que diz respeito ao pensamento sobre as instituições escolares e artísticas como lugares próprios à normalização e à produção de comportamentos civis desejados e padronizados. 


\section{UMA GUERRA E UMA ESCOLA DE TEATRO}

A Guerra do Paraguai foi, conforme define o pesquisador Felipe Oswaldo Guimarães (2014), o mais longo conflito que o Brasil participou e a maior mobilização humana promovida no Império - mais de 100 mil soldados em terra, o que requereu uma reorganização do Exército, o qual ao fim do conflito contava com uma participação política bastante ativa no âmbito governamental. Fora isso, as dificuldades enfrentadas produziram, segundo Guimarães (2014), uma maior consciência de solidariedade entre oficiais e tropas, ou seja, teria se formado algo da ordem de uma identidade corporativa.

A participação de soldados de diversas províncias unidos em prol de um mesmo objetivo e o entusiasmo ante a vitória corroboraram para o crescimento do sentimento nacionalista entre os soldados e os demais habitantes da nação. A corporação passou por uma reforma na qual fora ampliada a mobilidade hierárquica por mérito, permitindo que os oficiais inferiores pudessem, agora, ascender profissionalmente e se fixar na carreira militar, em contraponto com o privilégio de nascimento dos cadetes que ocupavam os cargos de oficiais.

Em 1874, uma nova reforma militar propunha extinguir o recrutamento forçado e implementar o recrutamento via sorteio. Com isso o recrutamento passaria a ser centralizado pelo Estado. A formação dos soldados começou a ser um assunto frequente nos debates da organização. De1874 a 1876, criaram-se as Companhias de Aprendizes Militares, Companhias de Aprendizes Artífices e as Companhias de Aprendizes Marinheiros em “várias províncias do país, para a formação de recrutas ou oficiais inferiores e a fabricação de armamentos e materiais para suprimento do Exército e da Marinha”. (GUIMARÃES, 2014, p. 11)

O recrutamento, agora dado via instrução, coadunava-se ao modo como passou a se dar a instrução no âmbito da educação geral de um cidadão. A instrução nas escolas militares, de acordo com Foucault (2009), reconfiguraria a distribuição espacial dos alunos nas escolas em geral, de modo que o professor conseguisse ter sob seus olhos, ao mesmo tempo, todos os estudantes. Os ensinamentos 
passariam a ser dados simultaneamente a todos os educandos, ou seja, um mesmo enunciado seria ouvido e compreendido por todos os alunos presentes, no mesmo instante, no mesmo espaço físico. Assim, não se ensinaria qualquer coisa a qualquer momento. Haveria a necessidade de um ensino seriado, com etapas sequenciais e progressivas a serem cumpridas. Bem diverso, por exemplo, das escolas no período colonial em que não havia a necessidade desse ensino ser público, muito menos um direito de todos e os mestres proferiam lições em suas casas, mais preocupados com a iniciação dos educandos no mundo das letras.

Em 1871, o então Ministro da Guerra, José Maria da Silva, conhecido como Visconde de Rio Branco, declarou: “[...] a instrução, que se proporciona ao soldado, abre-Ihe mais possibilidade de aspirações, não só para a obtenção dos postos de oficiais inferiores, como até de matrícula no estabelecimento de instrução militar secundária e superior". (BRASIL, 1871 apud GUIMARÃES, 2014, p. 34)

O sistema de formação de tropas se modificou, presenciou-se a afirmação da importância da disciplina e do trabalho regrado. Os estabelecimentos de instrução militar se propunham a ser um meio de acolhimento do público desocupado e de correção dos comportamentos tidos como perigosos, logo, impeditivos à construção da nacionalidade e da cidadania entre os soldados. Um intenso apelo à figura de um soldado-cidadão, em contraposição ao mercenário ou ao soldado recrutado à força, passaria a vigorar:

\section{O recrutamento tem salvado da ociosidade e suas perigosas tendências a muitos indivíduos, que, vivendo inutilmente para a sociedade, encontrarão nas instituições militares pronto corre- tivo às suas faltas, e debaixo de severa vigilância reformarão os seus hábitos, ao passo que receberão instrução e preparar-se-ão para serem melhores cidadãos. (BRASIL,1871 apud GUIMARÃES 2014, p. 33)}

A presença dos desvalidos, entendidos como população marginal, desocupada e pobre, passaria a incomodar o Estado. Até então, eram as iniciativas religiosas ou ações filantrópicas que tradicionalmente assistiam o público abandonado, os órfãos etc. A centralização de tais questões no Estado expandiria a atuação do 
trabalho de proteção e salvação do indivíduo, uma vez que as instituições religiosas e filantrópicas se limitavam a presar pelos direitos individuais. Já o Estado gerenciaria, assistiria e regularia a produtividade dos indivíduos em sociedade. Inaugurava-se a construção de mecanismos cada vez mais sistemáticos e burocratizados de combate à pobreza. (GUIMARÃES, 2014) Dessa sorte, o Estado como provedor e responsável pelo bem-estar social do cidadão se fortaleceria na passagem do Império para a República.

Nas últimas décadas do século XIX, o ensino de ofícios começou a ganhar forças. Tal fenômeno contribuiria para a formação da noção de que a marginalidade, a pobreza, a vadiagem e a desocupação poderiam ser combatidas por meio da educação pública e da inserção produtiva dos cidadãos na sociedade. O Estado, portanto, começaria a formular propostas de recuperação e reinserção social das camadas menos privilegiadas da população via escolas de ofício. Surgem, neste contexto, as Escolas Agrícolas e Fazendas-Modelo, os Liceus de Artes e Ofícios, além da Escola Militar, todas sob a justificativa de formar cidadãos úteis a si mesmos e à pátria e, consequentemente, afastar os perigos que a criminalidade e o ócio ofertavam à paz e ao bem-estar. (GUIMARÃES, 2014)

Como se vê, da Campanha da Cisplatina à Guerra do Paraguai seria modificado o modo de se gerir não só o contingente do exército, mas a população como um todo. Todos os cidadãos deveriam ser moralmente educados e civilizados, quer fossem recrutas, atores, trabalhadores, jovens. Dessa forma, a ideia de uma formação profissional se estenderia não só aos soldados, mas também aos demais indivíduos, sob a alegação de que, com a educação pública e profissionalizante, seria possível construir uma nação próspera, com baixo índice de criminalidade e alta taxa de produtividade.

Uma das primeiras escolas de teatro a serem inauguradas oficialmente, Escola Dramática Municipal do Rio de Janeiro, criada em 1908, partiu da iniciativa de Henrique Maximiano Coelho Neto (1864-1934), poeta e membro da Academia Brasileira de Letras, sendo regulamentada dois anos depois pelo Decreto-Lei ${ }^{\circ}$ 832, de 8 de junho de 1910. 
Em 1916, Coelho Neto lavrara, junto com outros intelectuais e militares da época, a Liga da Defesa Nacional, uma das grandes responsáveis pela implementação do recrutamento dos soldados via sorteio, procedimento que até então não havia sido instituído, e, como já visto, foi fruto da Guerra do Paraguai. A Liga tinha como objetivo despertar os valores da Pátria e incutir entre os jovens e os militares o sentimento de nacionalidade. Por meio da revista Defesa Nacional, seus integrantes puderam colocar em circulação valores de civismo e cidadania valendo-se do conceito de cidadão-soldado e levantando como bandeira a premissa de que a causa da defesa da pátria deveria contar com a participação de toda a sociedade.

Ora, a ideia de que o teatro poderia incutir sentimento de patriotismo nos jovens, a este ponto, já não é novidade. Conforme identificado nos discursos de João Caetano dos Santos, portanto, desde os primórdios do século XIX, investia-se piamente no teatro como instrumento de conscientização ao patriotismo, uma vez que se acreditava que a sua prática contribuiria sobremaneira para a unificação nacional, em prol da constituição de bens comuns, fundamentais à fundação do imaginário de nação.

Para a primeira turma da escola de Coelho Neto inscreveram-se 138 candidatos, dos quais foram selecionados somente trinta estudantes (ANDRADE, 2009) quantia significativa se levarmos em conta a experiência anterior de João Caetano. As motivações e justificavas para a abertura da escola, assim se esboçavam:

\footnotetext{
E o incitávamos: "Mantenha o Dr. Coelho Neto a mesma atitude, prossiga com a mesma energia e implantará entre nós a carreira teatral, impelirá nossos escritores a produzir peças, e terá conseguido despertar - o que é infinitamente melhor - o gosto do nosso público pelo teatro genuinamente nacional!'. (NUNES, 1967 apud CARVALHO, 1989, p. 194-195)
}

Os primeiros professores da escola pertenciam à Academia Brasileira de Letras, assim como seu fundador, e a uma elite carioca intelectualizada, comprometida com a valorização de um teatro nacional. (ANDRADE, 2009) Contudo, a escola foi bastante criticada na época: “achavam-na emperrada, falha”. (CARVALHO, 
1989, p. 195) Após três anos do início da primeira turma, apenas quatro de seus estudantes se formaram. (ANDRADE, 2009)

Ao longo do século XX, instaura-se um processo de escolarização dos atores via instituições destinadas exclusivamente à sua formação. Estaria em curso uma grande armada em prol da fundação de escolas profissionalizantes de teatro. Era corriqueira a divergência de ideias entre aqueles que acreditavam ser a escola de atores algo inútil - a grande maioria dos partidários dessa ideia eram os atores consagrados da época -, e aqueles que defendiam arduamente a edificação de estabelecimentos educacionais para o ensino de teatro para atores - entre esses, membros da elite intelectual, políticos, formandos em letras ou direito, os quais identificavam nas artes cênicas propósitos de elevado alcance social, contribuindo para o aprimoramento do nível cultural do povo brasileiro, além de inspirar novos hábitos em quem fosse se candidatar à profissão:

O que nosso teatro pede no momento são elementos de formação cultural, técnica e profissional, completa. Chega de tentativas, de remendos, de improvisações. Para a 'formação' desse novo pessoal de teatro são necessárias 'escolas de teatro' a exemplo do que se faz no estrangeiro. (MESQUITA, 1948 apud SILVA, 1989, p. 51)

As manifestações teatrais passariam pelo processo de oficialização de sua prática como um ofício regulamentado pari passu com o provimento das bases de seu ensino como profissão. Paradoxalmente, no projeto político dos governos nacionais mais coercitivos é que tais medidas regulatórias foram tomadas. Na era Vargas (1930-1945), criou-se o Serviço Nacional de Teatro (SNT) e o Curso Prático de Teatro (CPT), pelo então Ministro da Educação e Saúde, Gustavo Capanema, via Decreto-Lei n 92, de 21 de dezembro de 1937, designado a “animar o desenvolvimento e o aprimoramento do teatro brasileiro". Competia ao SNT: a. promover ou estimular a construção de teatros em todo o país; b. organizar ou amparar companhia de teatro declamatório, lírico, musicado e coreográfico; c. orientar e auxiliar, nos estabelecimentos de ensino, nas fábricas e outros centros de trabalho, nos clubes e outras associações, ou ainda isoladamente, a organização de grupos amadores de todos os gêneros; d. incentivar o teatro para crianças 
e adolescentes, nas escolas e fora delas; e. promover a seleção dos espíritos dotados de real vocação para o teatro, facilitando-Ihes a educação profissional no país ou no estrangeiro.

Para Fuser (2012), coube ao CPT do SNT a instalação de um ensino formal com funcionamento regular e ininterrupto, contribuindo, dessa forma, para o amadurecimento do pensamento artístico e “[...] alterando sensivelmente a qualidade dos novos atores dispostos a entrar no mercado de trabalho em transformação". (FUSER, 2012, p. 459)

O Teatro Escola, concebido por Renato Viana, foi fundado em 1942, com subvenção do Ministério da Educação e Saúde, também durante o governo Vargas. Essa escola daria origem ao Curso de Arte Dramática da Universidade Federal do Rio Grande do Sul, em 1958. Para Fuser, Viana seria um agente primordial na causa da consolidação do ensino formal para atores entre 1920 e 1940.

Ainda na era Vargas, a Universidade de São Paulo (USP) foi criada por decreto de Armando de Salles Oliveira, nomeado interventor por Getúlio Vargas, no dia 25 de janeiro de 1934, e pretendia constituir-se como um "centro de renovação e formação das elites culturais e políticas". (BRITO, 2011, p. 47) 0 irmão mais velho de Alfredo Mesquita, fundador da Escola de Arte Dramática de São Paulo, e também membro da Liga de Defesa Nacional, Júlio de Mesquita Filho, foi um dos envolvidos no projeto de criação da Universidade junto a outros dirigentes do jornal O Estado de São Paulo, entre eles o já citado Armando de Salles, também sócio do jornal e cunhado de Júlio de Mesquita. (HECKER, 2009)

Assim foi criada a Faculdade de Filosofia, Ciência e Letras da USP, onde se formariam Décio de Almeida Prado, Gilda de Mello e Souza, Antonio Candido, Lourival Gomes, Paulo Emílio Gomes e Ruy Coelho, alguns dos quais formaram o Grupo Universitário de Teatro (GUT), em 1943, sob apoio financeiro do Fundo de Pesquisa Universitário. Décio de Almeida Prado, fundador do grupo, se aproximaria de Alfredo Mesquita por conta de sua atividade teatral, o que renderia profundos laços de parceria. O primeiro foi professor da escola de Alfredo Mesquita e peça fundamental no processo de anexação da Escola de Artes Dramáticas à USP. 
Durante o período da ditadura militar (1964-1985) foi reconhecida a formação do ator em nível médio pela promulgação da Lei n 4.641, de 27 de maio de 1965 (Lei Castelo Branco). Essa foi a primeira medida para regular os cursos em funcionamento para nível técnico profissionalizante, mantendo a formação técnica em nível médio para ator, contra-regra, cenotécnico e sonoplasta, e formação superior para diretor de teatro, cenógrafo e professor de arte dramática, além de regulamentar as categorias profissionais do teatro. Ao longo do período essa resolução sofreu pequenas alterações, chegando à configuração atual pela Lei $n^{\circ} 6.533 / 1978$, a qual determina que:

Com a educação planejada, àquele ‘espontanéismo, erroneamente identificado com o carater brasileiro, que originava a improvisação e levava à dispersão dos recursos disponiveis' - Ministro Jarbas Passarinho - os nossos atores, atualizados, conscientizados seus direitos e obrigações, intelectualmente preparados, poderão caminhar com segurança para uma plena realização profissional, contribuindo para o aprimoramento do nível cultural do povo brasileiro. (BRASIL, 1973, p. 6-15)

Ainda no período da ditadura militar, seria reconhecida a formação do ator em nível superior. Nesse contexto, por exemplo, seria criada a atual Escola de Comunicações e Artes da USP e o curso de Bacharel em Artes Cênicas.

Nota-se, portanto, que a convocatória proferida pelo dramaturgo e diretor de teatro Roberto Alvim, nos idos do ano de 2019, em prol da edificação de um Teatro Nacional e de uma "grande escola de teatro", não soa como inaugural, mas sim como reminiscência das vozes nacionalistas e patrióticas do século XIX. Delay emancipatório que traz consigo a novidade de que, atualmente, essa vertente teatral teria de se haver com uma suposta contracorrente ideológica: as práticas teatrais ditas progressistas, às quais se oporiam a preceitos conservadores e estariam empenhadas na implementação de efetivas políticas públicas para o teatro. 


\title{
DOIS TEATROS, DUAS IDEOLOGIAS. UM FIM?
}

Em seu legado, Foucault ressalta que a noção de ideologia requer cautela ao ser empregada por conta de três razões:

\begin{abstract}
A primeira é que, queira ou não, ela está sempre em oposição virtual a alguma coisa que seria a verdade. Ora, creio que o problema não é de se fazer a partilha entre o que num discurso releva da cientificidade e da verdade e o que relevaria de outra coisa; mas de ver historicamente como se produzem efeitos de verdade no interior de discursos que não são em si nem verdadeiros nem falsos. Segundo inconveniente: refere-se necessariamente a alguma coisa como o sujeito. Enfim, a ideologia está em posição secundária com relação a alguma coisa que deve funcionar para ela como infraestrutura ou determinação econômica, material, etc. Por três razões creio que é uma noção que não deve ser utilizada sem precauções. (FOUCAULT, 2009, p. 7)
\end{abstract}

A noção de ideologia, portanto, estaria inserida na maquinaria dos jogos de veredicção, ou seja, jogos entre verdadeiro e falso que se somam ao real transmudando-o, transformando-o (FOUCAULT, 2016), coadjuvando a constituição da experiência de sujeitos e de suas próprias verdades.

Ora, parece-nos que os protagonistas do embate virtual disparador desta reflexão são conscientes no que tange à tal cautela. Elegendo como arma deste conflito uma espécie de autodesresponsabilização ideológica, via acusação do caráter ideológico da discursividade do outro, ambas as trincheiras desses exércitos teatrais, ainda que ocupando polos opostos, partem para um combate em prol de um mesmo objetivo: ser útil à cena teatral de seu país.

Pelo exposto até então, apercebe-se do fato de que da Campanha da Cisplatina à Guerra do Paraguai teria sido desencadeado um amplo processo de espraiamento das tecnologias de gestão do exército para o governo da população como um 
todo, sendo atingidas por este contexto igualmente as práticas teatrais. Todos os cidadãos deveriam ser moralmente educados e civilizados, quer fossem recrutas, atores, trabalhadores, jovens. Dessa forma, a ideia de uma formação profissional se estenderia não só aos soldados, mas também aos demais indivíduos, sob a alegação de que, com a educação pública e profissionalizante, seria possível construir uma nação próspera, com baixo índice de criminalidade e alta taxa de produtividade. Sendo assim, a matriz de organização militar inspiradora das práticas teatrais em solo nacional - cujos ecos ainda hoje são audiveis -, interessada na constituição de cidadãos que dedicariam suas vidas à dignificação da humanidade, revelaria certo deslocamento da ideia de soldado militar, o qual ofereceria sua força física e sua vida pela pátria, em direção ao artista teatral, espécie de soldado dos palcos, o qual ofertaria igualmente a sua força física, materializada em presença cênica. Entretanto, o grande trunfo deste soldado dos palcos seria outorgar sua capacidade sensível e criativa, arma fundamental ao propósito de despertar o exercício simbólico em seu exército de espectadores, aos modos de uma potente máquina de guerra cultural.

Portanto, da constituição da escola formal, teatral ou militar, às práticas teatrais contemporâneas, sejam estas de filiação conservadora, interessadas na retomada dos clássicos e no desvelamento da complexidade humana, ou de filiação progressista, interessadas em processos libertários e em efetivas políticas públicas, também por isso tomadas como propulsoras de ideologias anarco-marxistas, o que se apresenta é uma profusão de discursos inter-relacionados, constitutivos de toda uma rede de alianças, de comunicações e pontos de apoio, interessados na estruturação dos campos de atuação de si por si, de si pelos outros, e dos outros por si. Ou seja, estamos a falar das práticas de governamento esclarecidas por Foucault como o emaranhado de tecnologias de dominação sobre os outros e as tecnologias de si.

Isso posto, ainda que divulgados como ideologicamente opostos, os discursos de Alvim e Abreu encontram-se empalheirados no que tange ao interesse de constituir experiências e verdades, fomentando processos de aprimoramento intenso de liberdades reguladas, uma vez que as escolhas dos sujeitos implicados, ainda que influenciadas por uma pletora incontestável de comandos externos, seriam livremente e voluntariamente operadas pelos próprios sujeitos. (ROSE, 
2011) No âmago dessa guerra, restaria ao sujeito supostamente autônomo, como

manifestação do exercício de sua liberdade, por suposto cerceada, escolher ser governado de uma ou de outra forma. (FOUCAULT, 1990) Cabe indagar: afinal, de qual liberdade estamos a falar?

\section{REFERÊNCIAS}

ABREU, K. [Artistas pelo Impeachment]. São Paulo, 19 jun. 2019. Facebook: kilabreu.

Disponivel em: https://www.facebook.com/kil.abreu. Acesso em: 24 jun. 2019.

ALVIM, R. [Página Inicial]. São Paulo, 18 jun. 2019. Facebook: robertoalvim. Disponível em: https:// www.facebook.com/roberto.alvim.9. Acesso em: 22 jun. 2019.

ANDRADE, E. Escola de teatro Martins Pena: a primeira escola de teatro no Brasil. O Percevejo, Rio de Janeiro, v. 1, 2009. Não Paginado. Disponivel em: http://www.seer.unirio.br/index.php/ opercevejoonline/article/view/534/490. Acesso em: 20 fev. 2018.

BRASIL. Decreto-Lei no 92, de 21 de dezembro de 1937. Cria o Serviço Nacional de Teatro. Diário Oficial da União: seção 1, Rio de Janeiro, p. 25585, 27 dez. 1937.

BRASIL. Lei n 1.233, de 9 de março de 1973. Exige habilitação profissional para o exercício da profissão de ator. Diário Oficial da União: seção 1, Brasília, DF, p. 3, 9 mar. 1973. Disponível em: http://www.camara.gov.br/proposicoesWeb/prop_ mostrarintegra;jsessionid=B268AF87A253ECC6C18B8C85541C12E8. proposicoesWeb1?co dteor=1188958\&filename=Avulso+-PL+1233/1973. Acesso em: 25 jun. 2019.

BRASIL. Lei n ${ }^{\circ}$ 4.641, de 27 de maio de 1965. Dispõe sôbre os cursos de teatro e regulamenta as categorias profissionais correspondentes. Diário Oficial da União: seção 1, Brasília, DF, 31 maio 1965. BRASIL. Lei nº 6.533, de 24 de maio de 1978. Dispõe sobre a regulamentação das profissões de Artistas e de técnico em Espetáculos de Diversões, e dá outras providências. Diário Oficial da União: seção 1, Brasília, DF, 25 maio 1978.

BRITO, P. M. F. A (in)desejada transgressão: uma história social do ensino superior de teatro no Brasil. 2011. Dissertação (Mestrado em Educação) - Faculdade de Educação, Universidade de São Paulo, São Paulo, 2011.

CARVALHO, E. História e formação do ator. São Paulo: Ática, 1989.

FARIA, J. R.; GUINSBURG, J. (org.). História do teatro brasileiro. São Paulo: Edições SESC SP: Perspectiva, 2013.

FOUCAULT, M. Estratégia, poder-saber. 2. ed. Rio de Janeiro: Forense Universitária, 2006. (Ditos \& escritos, v. 4).

FOUCAULT, M. Microfísica do poder. Rio de Janeiro: Graal, 2009. 
FOUCAULT, M. Qu'est-ce que la critique? [Critique et Aufklärung]. Bulletin de la Société française

de philosophie, Charlottesville, v. 82, n. 2, p. 35-63, 1990. Disponível em: http://michel-foucault. weebly.com/uploads/1/3/2/1/13213792/critica.pdf. Acesso em: 25 jun. 2019.

FOUCAULT, M. Subjetividade e verdade: curso no Collège de France (1980-1981). São Paulo: Martins Fontes, 2016.

FOUCAULT, M. Tecnologias de si, 1982. Verve, São Paulo, n. 6, p. 321-360, 2004. Disponível em: https://revistas.pucsp.br/verve/article/view/5017. Acesso em: 28 jul. 2019.

FOUCAULT, M. Vigiar e punir: nascimento da prisão. 11. ed. Petropolis: Vozes, 1994.

FUSER, R. A. B. A Formação do ator. In: GUINSBURG, J.; FARIA, J. R. (ed.). História do teatro brasileiro: do modernismo às tendências contemporâneas. São Paulo: Edições SESC SP, 2012. v. 2. p. 460-564.

GUIMARÃES, F. O. Formação militar e "amparo aos desvalido" na companhia de aprendizes militares de Minas Gerais (1876-1891). 2014. Dissertacão (Mestrado em Educação) - Faculdade de Educação, Universidade Federal de Minas Gerais, Belo Horizonte, 2014.

HECKER, H. H. Alfredo Mesquita: teatro e crítica na São Paulo de 1940 a 1960. 2009. Dissertação (Mestre em Artes) - Instituto de Artes, Universidade Estadual Paulista, São Paulo, 2009.

HOLANDA, S. B.; PINHEIRO, P. S.; FAUSTO, B. (org.). História geral da civilização brasileira, o Brasil republicano: sociedade e instituições (1889-1930). 8. ed. Rio de Janeiro: Bertrand Brasil, 2006.

v. 9. t. 3.

JUNQUEIRA, L. F. A Bahia e o prata no primeiro reinado: comércio, recrutamento e guerra cisplatina (1822-1831). 2005. Dissertacão (Mestrado em História) - Faculdade de filosofia e ciencias humanas, Universidade Federal da Bahia, Salvador, 2005. Disponível em: https:// repositorio.ufba.br/ri/bitstream/ri/11345/1/Dissertacao\%20Lucas\%20 Junqueiraseg.pdf. Acesso em: 28 jul. 2019.

MAGALDI, S. A. Panorama do teatro brasileiro. 3. ed. São Paulo: Global, 2001.

MORAES FILHO, A. J. M. João Caetano: estudo de individualidade. Rio de Janeiro: Laemmert, 1903.

ROSE, N. Inventando nossos selfs: psicologia, poder e subjetividade. Petrópolis: Vozes, 2011.

SANTOS, J. C. Lições dramáticas. Rio de Janeiro: Departamento de Imprensa Nacional, 1956.

SILVA, A. S. Uma oficina de atores: a escola de arte dramática de Alfredo Mesquita. São Paulo: Ed. USP, 1989. (Comunicações \& artes).

SOUZA, M. R. S. A lei do recrutamento militar de 1874 e as resistências abertas a esta nas províncias do norte do Brasil (1875). In: ENCONTRO INTERNACIONAL DE JOVENS INVESTIGADORES, 6., 2013, Salvador. Anais [...]. Salvador: JOIN, 2013. Disponível em: https:// www.editorarealize.com.br/revistas/joinbr/trabalhos/TRABALHO_EV081_MD1_SA141_ ID1025_28082017134803.pdf. Acesso em: 28 jul. 2019. 

Maringá.

Priscilla Carbone: é mestra em Artes Cênicas pela ECA-USP, pesquisadora e docente de teatro do SENAC-SP. 